\title{
LA-UR-20-28923
}

Approved for public release; distribution is unlimited.

Title: Los Alamos Applied Energy Programs

Author(s): $\quad$ Guthrie, George Drake Jr.

Fox, Melissa Miller

Intended for: Various briefings

Issued:

2020-11-02 
Disclaimer:

Los Alamos National Laboratory, an affirmative action/equal opportunity employer, is operated by Triad National Security, LLC for the National Nuclear Security Administration of U.S. Department of Energy under contract 89233218CNA000001. By approving this article, the publisher recognizes that the U.S. Government retains nonexclusive, royalty-free license to publish or reproduce the published form of this contribution, or to allow others to do so, for U.S. Government purposes. Los Alamos National Laboratory requests that the publisher identify this article as work performed under the auspices of the U.S. Department of Energy. Los Alamos National Laboratory strongly supports academic freedom and a researcher's right to publish; as an institution, however, the Laboratory does not endorse the viewpoint of a publication or guarantee its technical correctness. 


\section{Los Alamos Applied Energy Programs}

"Energy security is national security" Lisa Gordon-Hagerty, NNSA Administrator

- Los Alamos NATIONAL LABORATORY

EST.1943
Melissa Fox (Program Director) George Guthrie (Deputy Program Director)

October 2020 


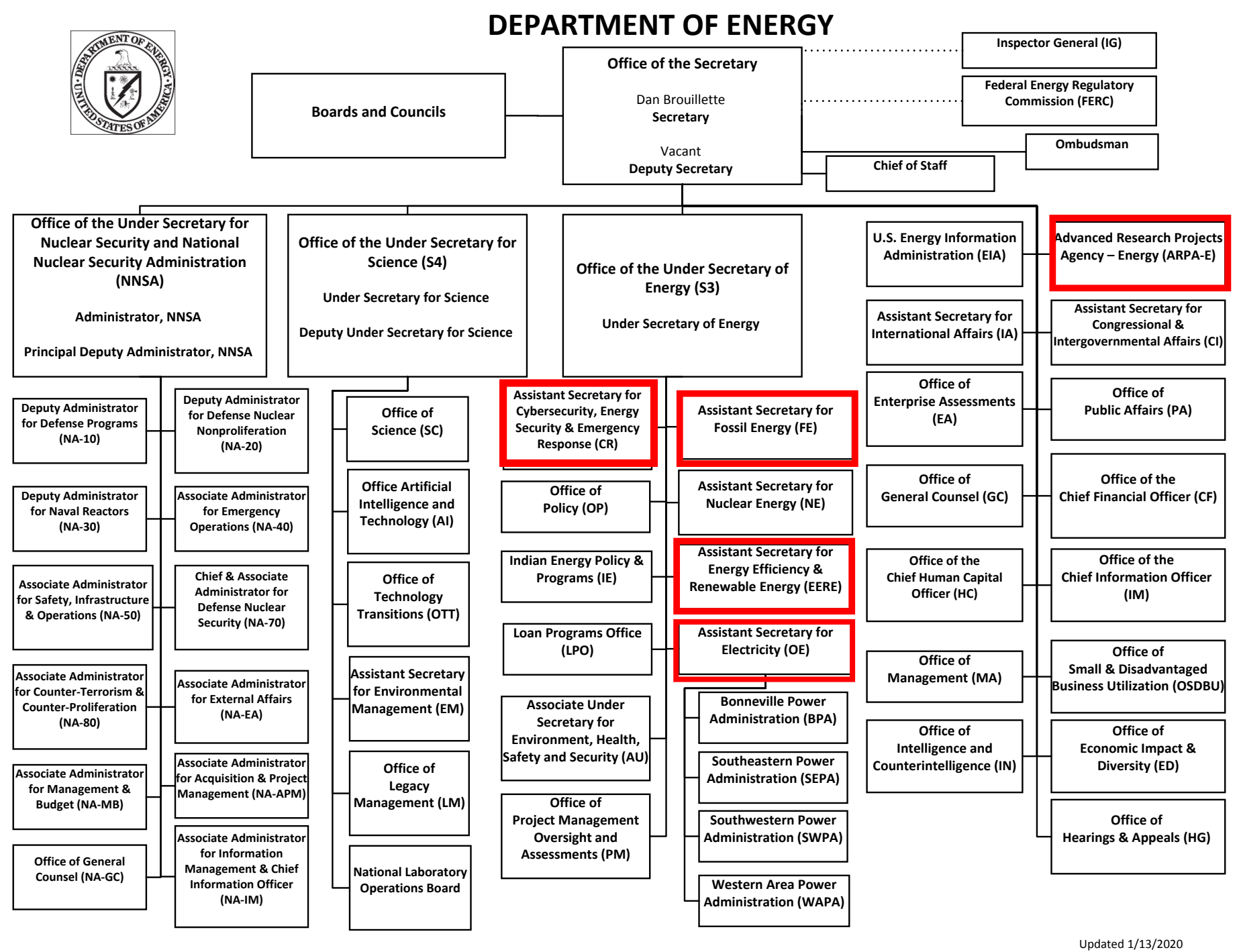




\section{Los Alamos Contributes to DOE Energy Programs}

\section{Energy Efficiency and Renewable Energy (EERE)}

- Vehicle Technologies

- Bioenergy Technologies

- Hydrogen and Fuel Cells Technologies

- Geothermal Technologies

- Wind Energy Technologies

- Advanced Manufacturing

\section{Advanced Research Projects} Agency-Energy (ARPA-E)

Transformational energy projects

\section{Office of Electricity (OE)}

- Advanced Grid Research \& Development

- Energy Storage

- Microgrid Research \& Development

- Grid Modernization Laboratory Consortium

\section{Cybersecurity, Energy Security,} and Emergency Response (CESER)

- Cybersecurity for Energy Delivery Systems

- Infrastructure Security \& Energy Restoration

\section{Office of Fossil Energy (OFE)}

- Carbon Storage

- Carbon Capture

- Unconventional Technologies

- Advanced Energy Systems
- Cross-cutting Research (rareearth elements; materials in extreme conditions 


\section{Applied Energy Multi-institutional Partnerships}

NiRAP Nationa Risk

ARAP, Assessment Patrestestip
$8 \mathrm{CCI}^{2}$ Carbon Capture Simulation

$\mathrm{CCSI}^{2}$ for Industry Impact
PACE

Producing Algae for Coproducts and Energy
Fuel Cell

Performance and Durability
(3) ElectroCat $\begin{aligned} & \text { Electrocatalysis } \\ & \text { Consortium }\end{aligned}$

(3) ElectroCat $\begin{aligned} & \text { Electrocatalysis } \\ & \text { Consortium }\end{aligned}$

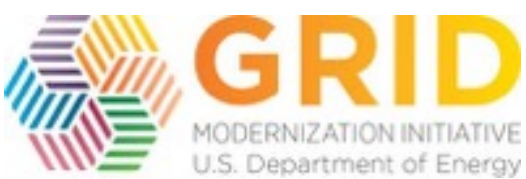

Grid Modernization Laboratory Consortium

In turn, our participation in partnerships supports and enriches the Lab's multidisciplinary capabilities 


\section{Energy Efficiency and Renewable Energy Portfolio}

\section{- Bioenergy}

- Advanced Algae Systems: Algae as a bio-feedstock for fuels and bioproducts; molecular tools to improve growth and productivity

- Feedstock and Logistics: Addressing woody biomass and corn stover processing bottlenecks

- Conversion: Technologies for conversion into biofuels, bioproducts, and biopower synthesis
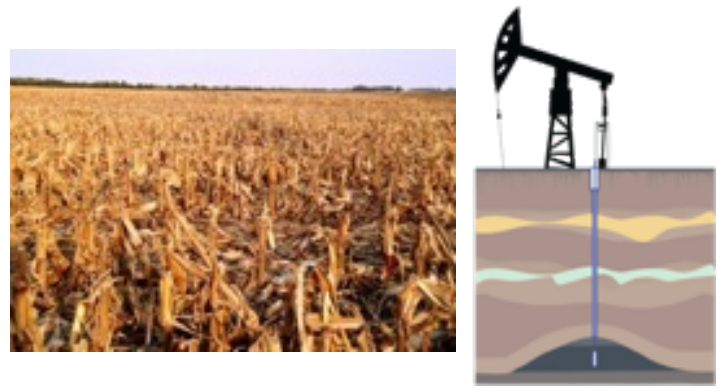

Crude oil

- Advanced Development and Optimization: Integrating individual technologies into a system/process

- Vehicle Technologies

- Developing an internal combustion model-FEARCE code helps engine designers understand combustion processes

- Fuel Cells

- Polymer Electrolyte Membrane (PEM) technology

- Focus on fundamental understanding for materials and process development - PGM-free catalysts, alkaline membranes, and enhancing durability of fuel cell components
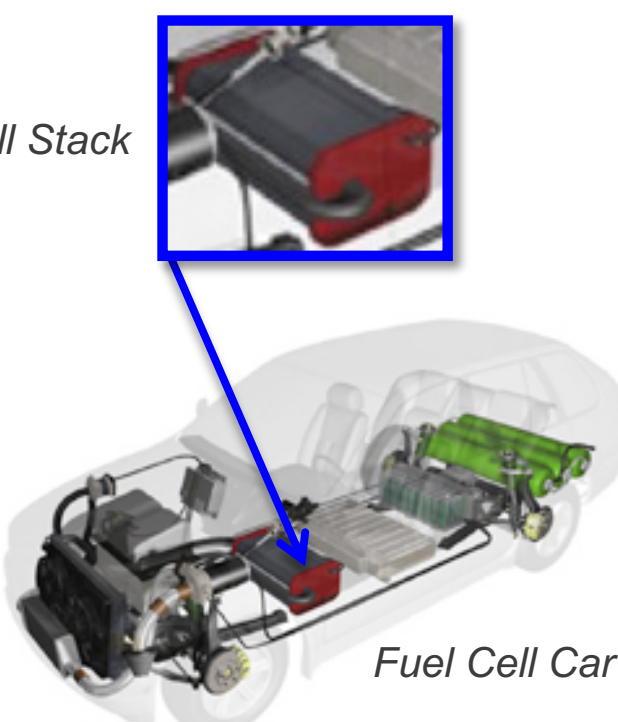


\section{DOE Plastics Innovation Challenge}

\section{A comprehensive DOE program to accelerate innovations in energy-efficient plastics}

\section{Bio-Opptimized Technologies for keeping Thermoplastics out of the Landfill and Environment (BOTTLE)}

\section{LANL Effort}

Use high throughput screening approaches to enable the rapid identification of new/improved enzymes for plastic deconstruction and upcycling

- Deconstruction (Task Co-lead): Focus on biobased deconstruction of plastics (nylon, polyurethanes)

- Upcycle \& Redesign: Enzyme and strain improvement, co-design with new polymers

- Participate in the leadership team

\section{LANL Capabilities Leveraged}

Computational protein design, strain and enzyme evolution, biosensor development
Delivering robust processes to upcycle existing waste plastics, and develop new plastics and processes that are recyclable-by-design

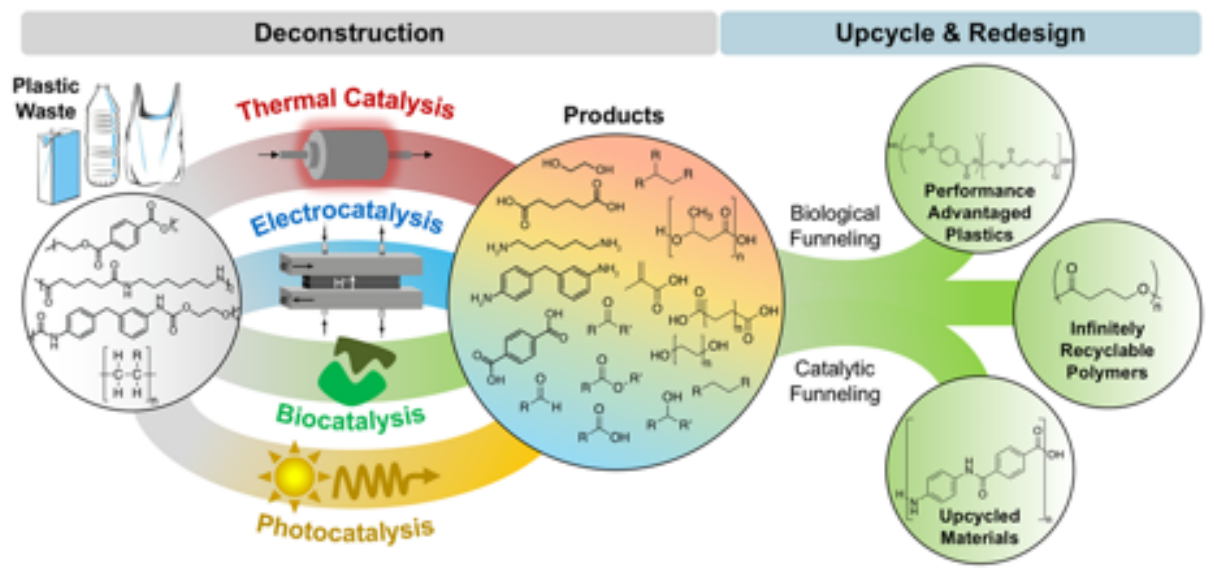

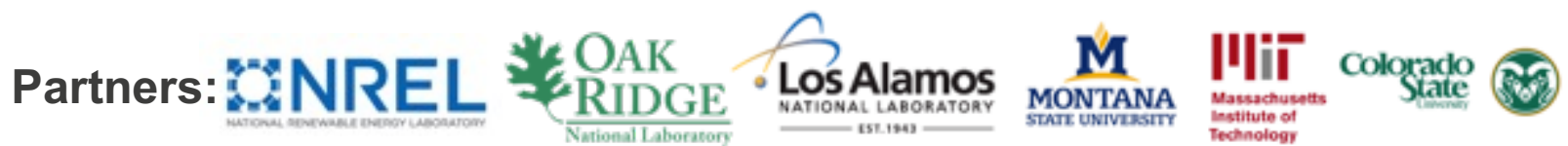




\section{Technical and Strategic Leadership in BOTTLE}

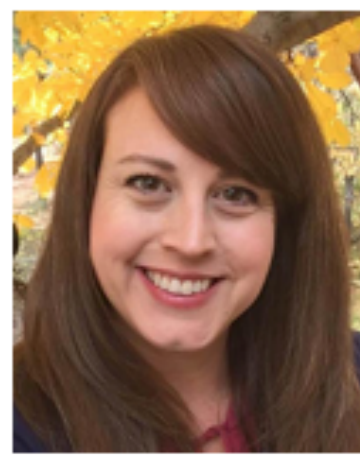

Technical and Consortium Leadership Taraka Dale, B-11

- High throughput screening expertise

- Strategic planning

- Structuring objectives, tasks, milestones

- R\&D prioritization

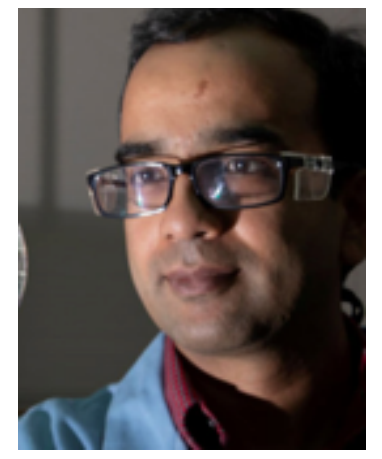

\section{Technical Leadership} Ramesh Jha, B-11

- Computational protein engineering

- Biosensor design and development

- High-throughput screening to enable plastic waste deconstruction and to improve its bioconversion into higher-value product
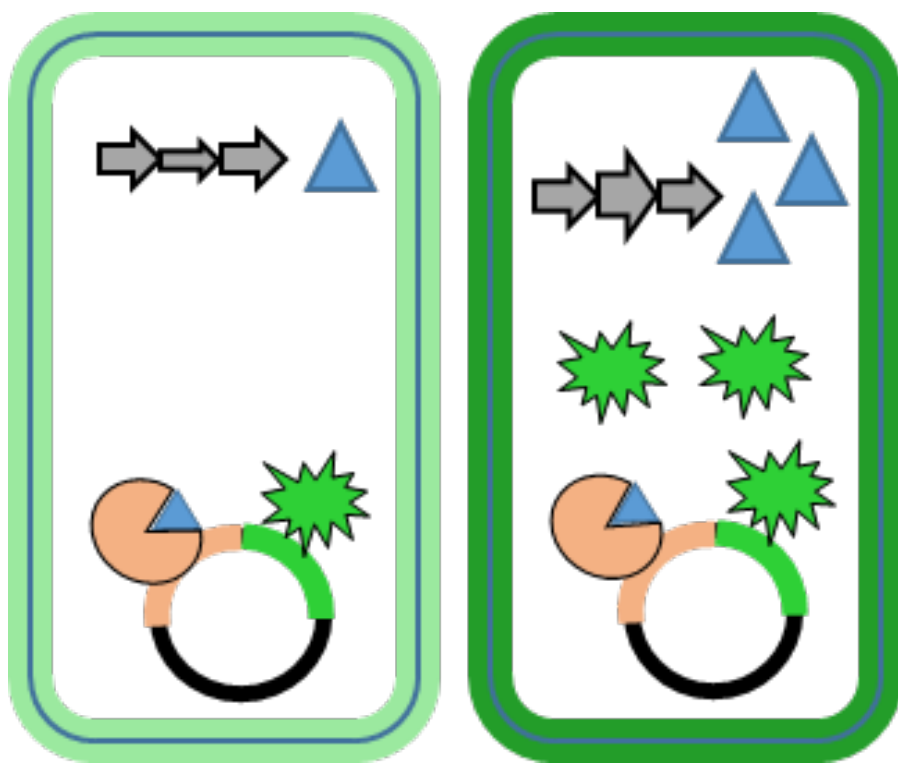

LANL's Smart Microbial Cell Technology will be used to rapidly report on deconstruction products and to improve new microbes for biological funneling and upcycling to new products. 


\section{Technical and Strategic Leadership in HFTO Consortia}

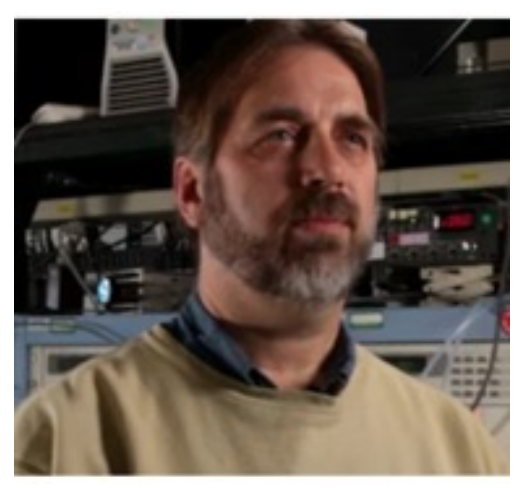

Fuel Cell Performance and Durability (FC-PAD) Rodney Borup, MPA-11, Director
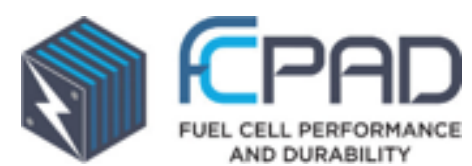

- Enhancing the performance and durability of polymer electrolyte membrane fuel cells while simultaneously reducing their cost

- Goal is to demonstrate world-class improvements in fuel cell performance and durability that exceed the targets set by the U.S. DOE

- Currently being re-competed as M2FCV (Million Mile Fuel Cell Vehicle), $\$ 10 \mathrm{M} / \mathrm{yr}$ for 5 years (LANL and LBNL co-lead)

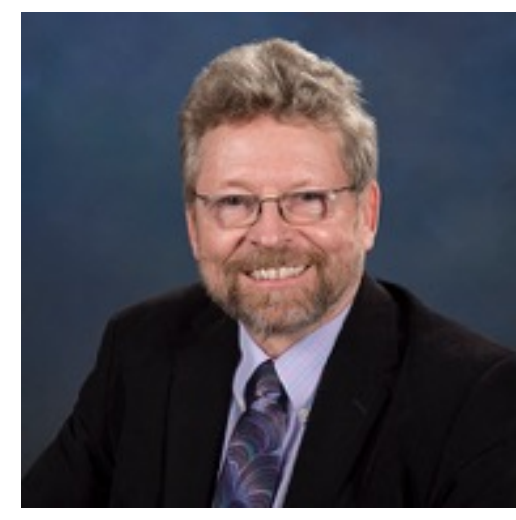

Electrocatalysis (ElectroCat) Co-Director: Piotr Zelenay, MPA-11

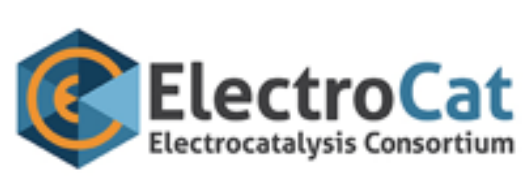

- Accelerating the development and deployment of platinum group metal-free (PGM-free) electrocatalysts in fuel cells

- Employs a systematic approach in which potential catalysts are synthesized and analyzed rapidly and comprehensively using high-throughput, combinatorial methods

- Currently being re-competed as ElectroCat 2.0, \$3M/yr for 3 years (LANL and ANL co-lead) 


\section{Energy Efficiency and Renewable Energy Portfolio}

\section{- Geothermal}

- 3D seismic images reveal vertically oriented faults and fractures to help determine optimal locations for drilling

- 3D acoustic imaging beyond the borehole for real-time monitoring of wellbore integrity

- Machine learning applied to geothermal systems 3 new projects funded in FY19

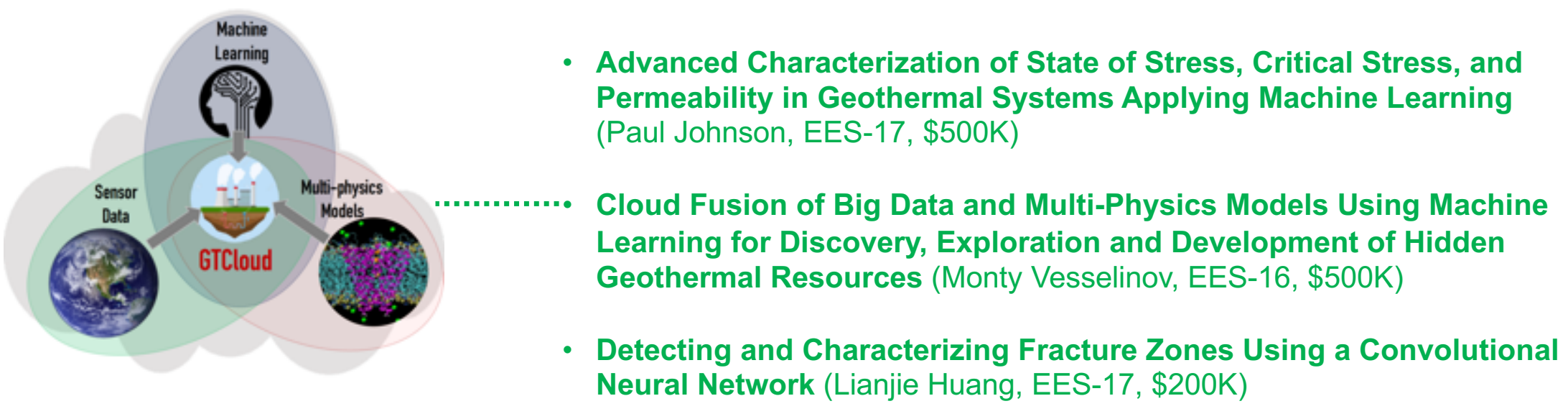

\section{- Wind}

- HPC code enables high resolution simulations of complex atmospheric and turbine blade interactions with the goal of increasing turbine reliability, performance and optimal placement 


\section{Fossil Energy Portfolio}

- Carbon Storage

- Predicting the integrity of seals and wellbores

- Multi-phase subsurface flow and transport modeling and prediction

- Novel methods to detect small leaks over large areas - seismic and acoustic imaging coupled with machine learning

- Monitoring for faults at a critical state of stress

\section{- Oil \& Gas}

- Modeling flow in fractured systems

- Prediction of fracture networks

- Physics-based analysis of production

- Carbon Capture

- Pre-combustion membrane separations

- Carbon Capture Simulation Initiative

- New computational tools and models to enable industry to more rapidly develop and deploy new advanced energy technologies
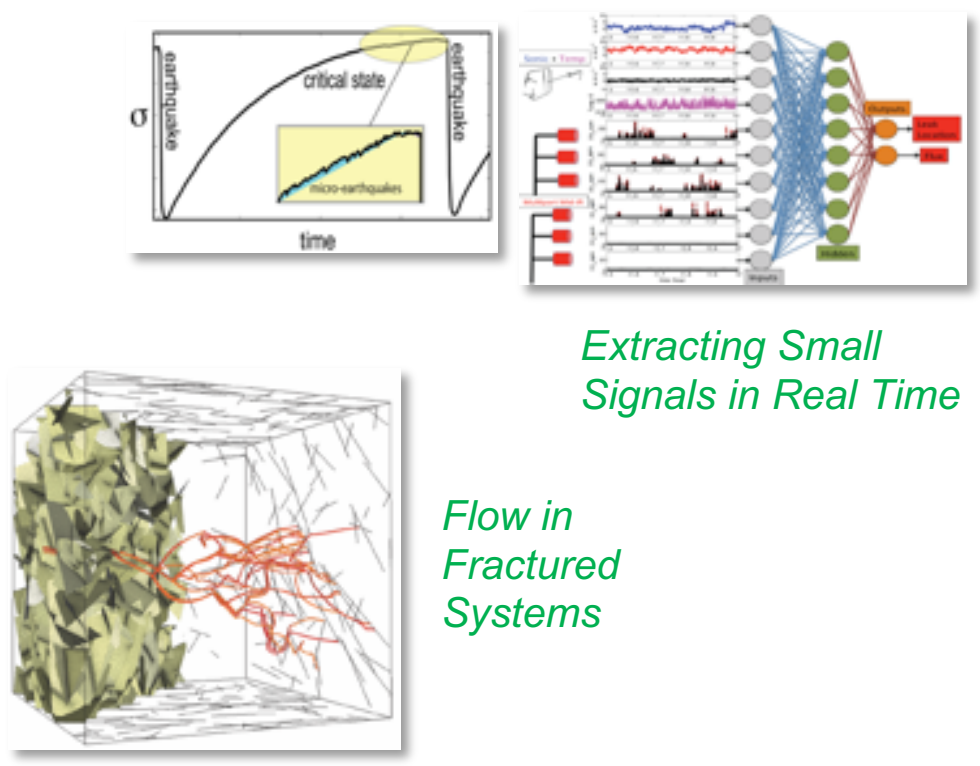

Extracting Small Signals in Real Time

Flow in

Fractured

Systems

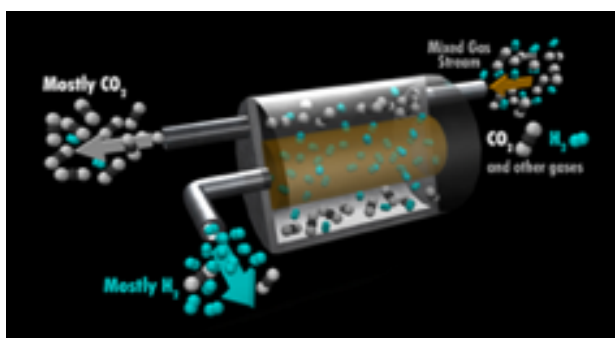

Membrane and Module Design, Evaluation, and Scale-Up 


\section{SMART Initiative is developing novel machine-learning applications to transform subsurface decisions.}
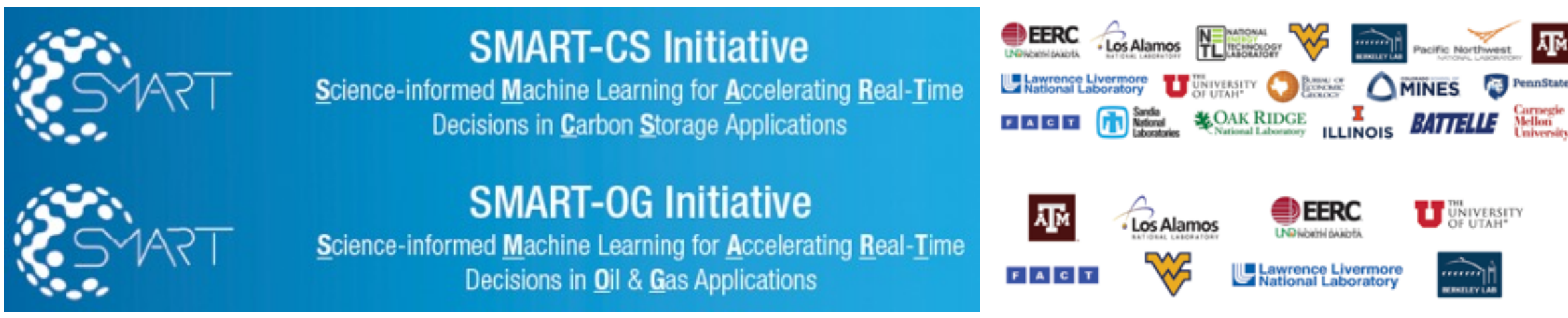

- New initiative targets improving real-time decisions for subsurface

- Combines accuracy and predictability of physics with speed of machine learning

- New challenges in fossil energy parallel challenges in national-security mission

- New signature identification (small signals, noisy background)

- Rapid prediction for complex, uncertain systems

- 10-year initiative, launched in summer 2019

- Initial (proof-of-concept) phase-2 years, $\sim \$ 20 \mathrm{M}$ from both FE-20 \& FE-30

- Oil/gas-Improve decisions on recovery \& economics for fractured reservoirs (e.g., shales)

- $\mathrm{CO}_{2}$-Improve decisions on monitoring \& operations of $\mathrm{CO}_{2}$ storage 


\section{Technical and Strategic Leadership in SMART}

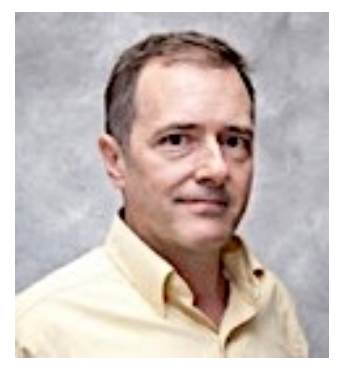

Strategic and Technical and Leadership

George Guthrie, SPO-AE

- Detail with DOE-FE and NETL to develop strategy and technical vision for initiative

- Serves on SMART Advisory Board

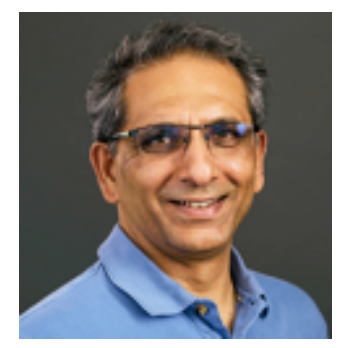

Technical Leadership

Rajesh Pawar, EES-16

- Lead for multi-organizational team focused on virtual learning for $\mathrm{CO}_{2}$ storage

- LANL lead for SMART-CS

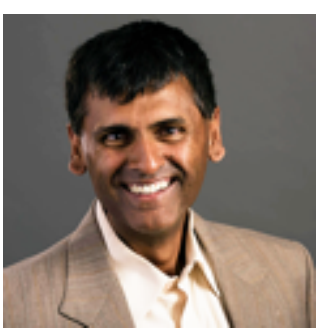

\section{Technical Leadership} Hari Viswanathan, EES-16

- Lead for multi-organizational team focused on virtual learning for shale-gas

- LANL lead for SMART-OG 


\section{Fossil Energy Portfolio - Crosscutting Research}

\section{- Rare Earth Elements}

- Establish alternate sources of rare earth elements (REE) to reduce dependence on foreign supply

- No domestic production since 2016

- Majority of mining/production from China

- Demonstrate the ability to use advanced dissolution techniques to leach REE from fly ash.

- Develop and test the ability to use advanced dissolution techniques and solvent extraction contactors to extract REE from coal-related materials

\section{- Extreme Environment Materials}

- eXtremeMAT will result in toolsets that address gaps in current physics-based materials modeling, data analytics, and machine learning

- Reliable prediction of materials performance over long service lifetimes in fossil energy power plant environments

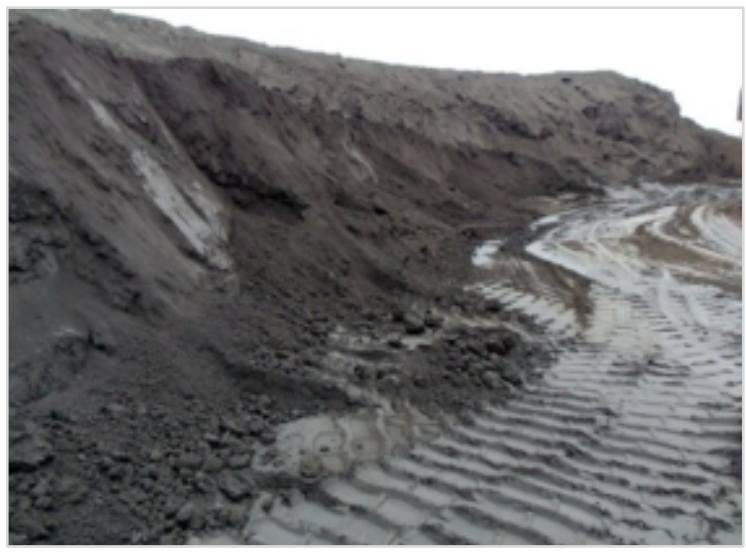

Fly ash, a solid by-product from burning coal, is investigated as an alternative REE resource

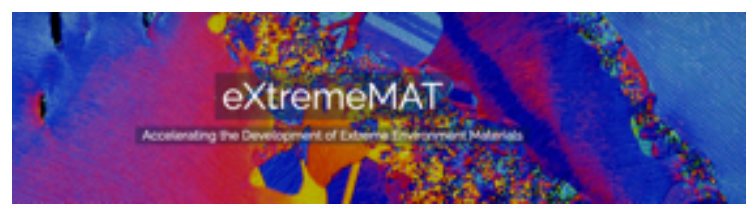




\section{eXtremeMAT Strategic and Technical Leadership}

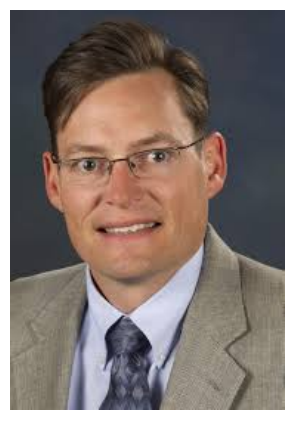

\section{Founding Strategic Leadership}

David Teter, MST

- Strategic leader of XMAT since inception; thought leader of overall program

- Developed relations with external stakeholders; harmonized interests of the various national laboratory partners

- Served as Chair of the the XMAT Stakeholder Advisory Board

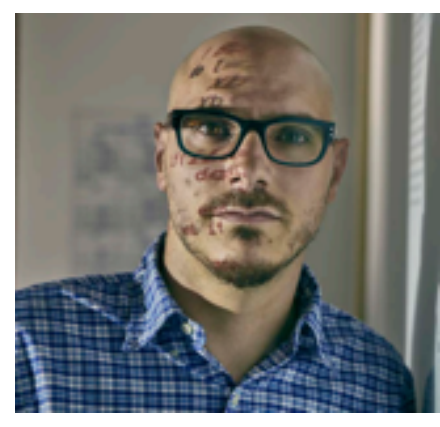

Current Technical and Strategic Leadership Laurent Capolungo, MST-8

- Lead author of XMAT 5-year plan, including technical direction, tasks, and technical objectives

- Leads work scoping for technical teams across national labs for all of XMAT

- Task 2 (modeling and simulation) technical lead

- Stakeholder engagement, budget and strategy planning, active participant on the XMAT Stakeholder Advisory Board 


\section{eXtremeMAT Wins and New Partnerships}

\section{Quick Win: New Modeling Capability}

- Predicts likelihood of material failure, differs from existing ASME type approaches (no uncertainty)

- Allows optimization of structural designs and rapid certification of new materials

- Considers materials aging, stress and temperature cycling

- Demonstration to DOE-FE of applicability

- Leveraged past work part of DoE NE-NEAMS and added new capabilities

- Significant interest from Siemens and Southern Company to test LANL models

\section{New Partnership with UTRC 影 United Technologies}

- HPC4 Materials project uses LANL models to extrapolate potential response of a new material (\$300K/year)

\section{XMAT Attracts New Talent}

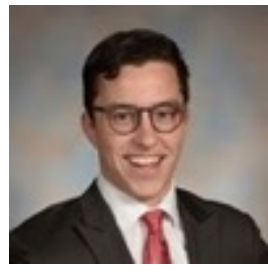

Nathan Bieberdorf (UC Berkeley) received a 2019 LANL Distinguished Student Award for his contributions
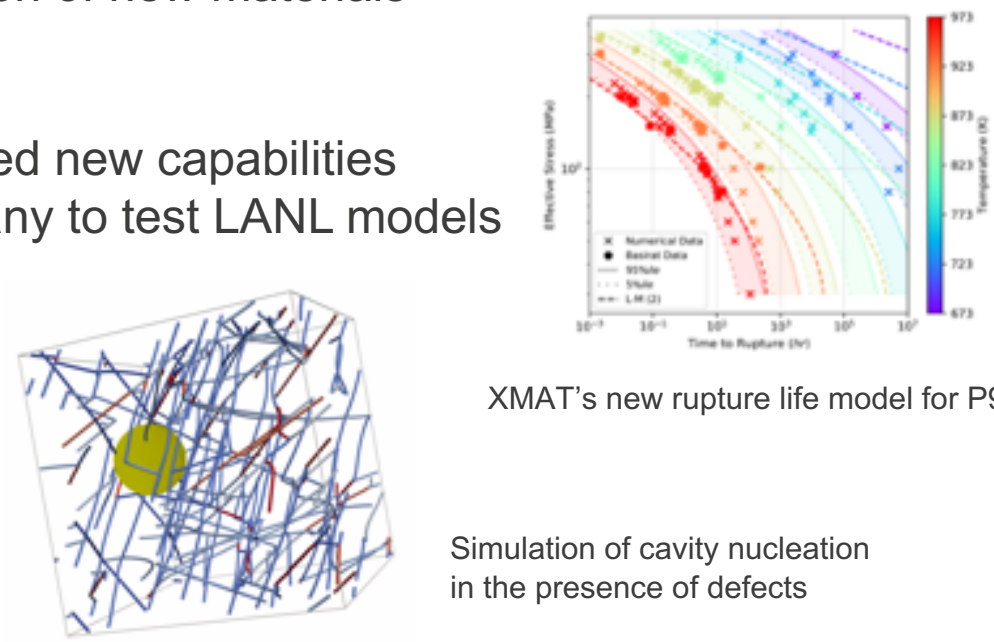

XMAT's new rupture life model for P91

Simulation of cavity nucleation in the presence of defects 


\section{Office of Electricity Portfolio}

\section{- Advanced Grid Modeling}

- Integrated Control and Optimization Under Uncertainty

- Develop new algorithms and models to mitigate the effects of uncertainty on electrical power systems and natural gas pipelines

- Interdependent Energy Networks

- Understand the propagation of stress, dynamics, uncertainty, and prices across power/gas networks to enable optimal operations

- Apply physics-inspired machine learning to difficult power systems applications

- Design of Resilient Power Systems

- Optimize design, hardening, and resilience upgrades of power systems to withstand and recover from extreme events

- Analysis of Extreme Events and Threats

- Independent, science-based evaluation of threats to infrastructure

\section{- Energy Storage}

- Non-aqueous Flow Batteries

- Develop flow batteries that are more scalable and flexible for grid scale energy storage - pursuing Fe and all organic

- Increase energy density by increasing voltage per redox couple and overall decrease the cost of flow cells

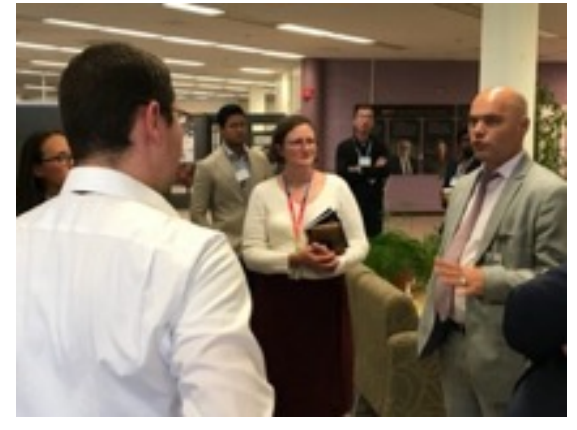

"LANL researchers are also providing key input into critical infrastructure protection... That work, in turn, will inform our Defense Critical Electric Infrastructure (DCEI) efforts."

Bruce Walker, Assistant Secretary, Office of Electricity 


\section{North American Energy Resilience Modeling (NAERM)}

A collaboration between DOE, national labs, and industry, the NAERM will ultimately provide real-time situational awareness and analysis capabilities for emergency events for optimal operations and recovery

- LANL's work on modeling, especially on the natural gas side, will inform the NAERM and future investments

- LANL researchers are providing key input into critical infrastructure protection

- This work will inform Defense Critical Electric Infrastructure (DCEI) efforts
Leveraging and Building Upon National Lab Research Investments

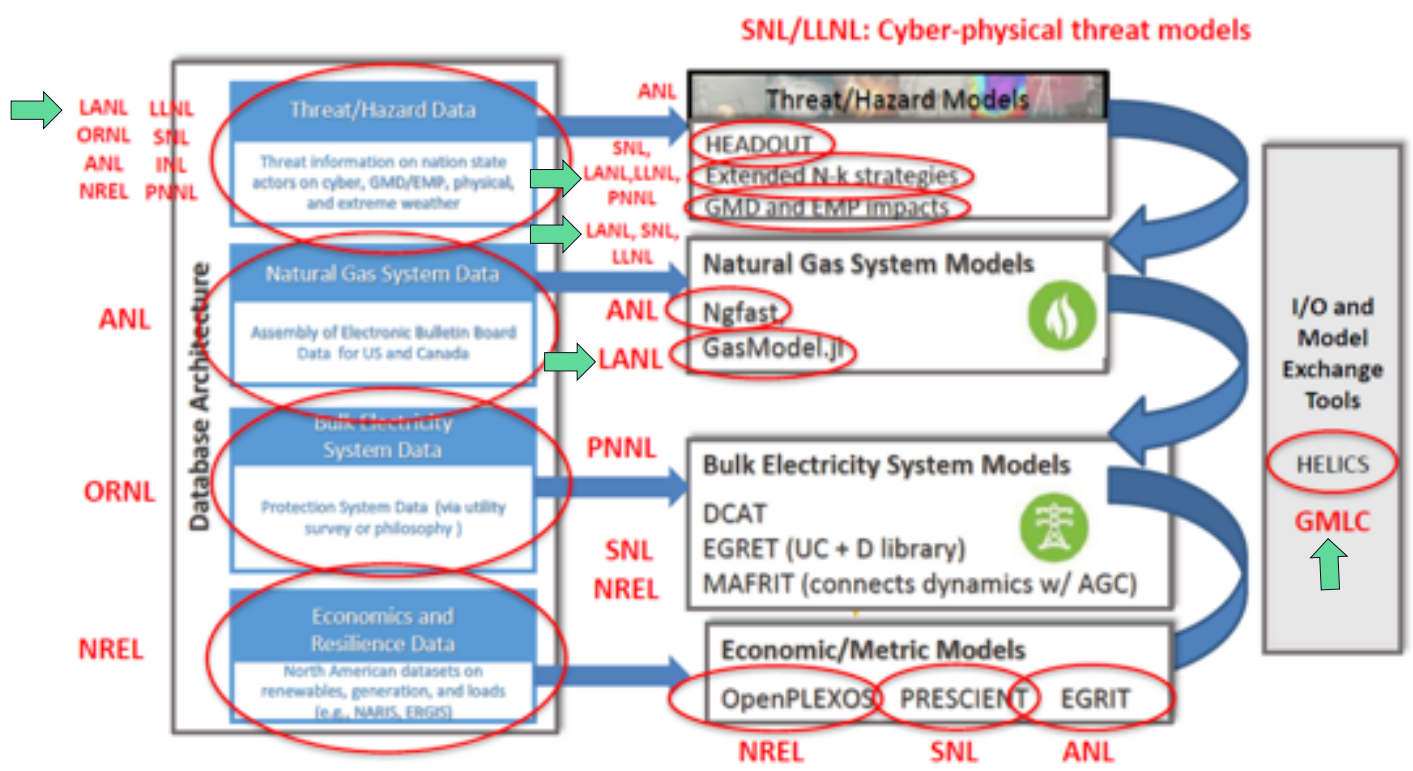




\section{NAERM Technical Leadership}

\section{Strategic and Technical Leadership}

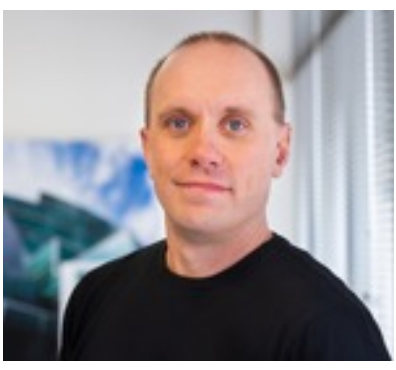

\section{Russell Bent, T-5}

- Contributed to DOE vision for NAERM

- LANL Co-chair of the NAERM natural gas domain

- Validation and verification of NAERM models

\section{NAERM Software}

Framework

Delivered September 2019

Natural Gas Hydraulic

Modeling Capability

To be delivered September 2020

advanced network science initiative (ansi)
NAERM leverages LANL capabilities in infrastructure science to address gas modeling needs

- GasModels.jl developed at LANL

- Enables computational evaluation of emerging gas network formulations and algorithms in a common platform

- OE funded project

- Efficient infrastructure utilization-improve deliverability of natural gas

- Gas market design and analysis--value-driven delivery of natural gas 


\section{Defense Critical Electric Infrastructure (DCEI)}

- LANL selected to develop a small scale microgrid on site to demonstrate resiliency

- Once hardware is installed, tests will be run to demonstrate that the microgrid is functional

- If successful, this demo will be an example for other DCEI sites, and OE will likely want to bring others (DoD) on site to demonstrate

- LANL is partnering with other labs on proposals for providing modeling tools that can assess vulnerabilities and, ultimately, develop prioritized mitigation strategies for DCEI sites

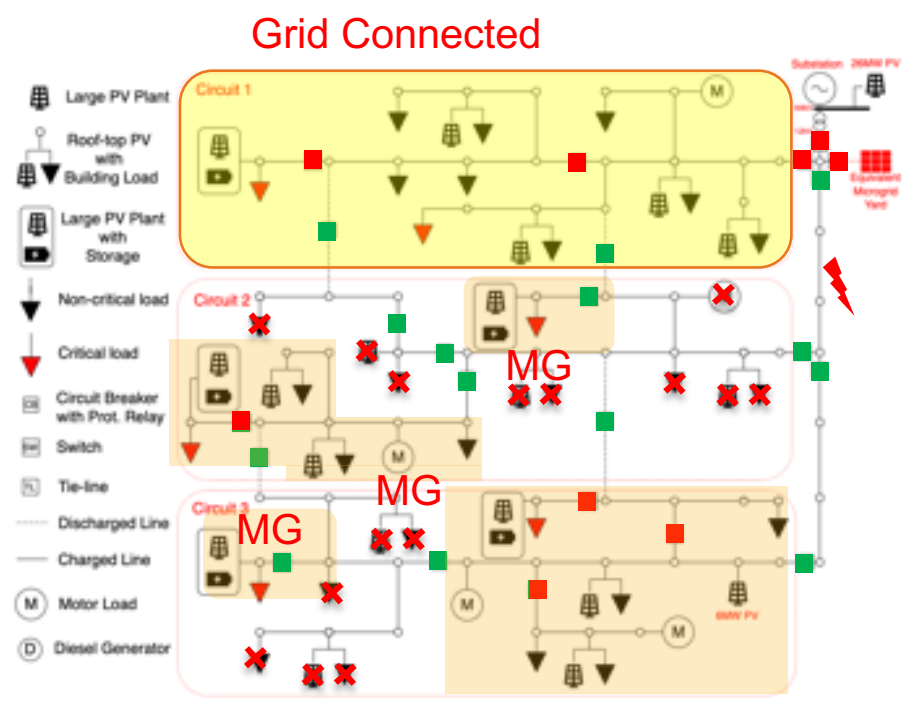

Resilient Operations of Networked Microgrids (Russell Bent, PI)

- Funded by DOE Microgrid Research and Development Program

- Objective: Improve resiliency of power systems with optimization-based methods

- Outcome: First-of-kind, high-fidelity physics-based optimization method for modeling networked microgrids

- LANL capabilities developed in this program will be leveraged for DCEI 


\section{Cybersecurity, Energy Security, and Emergency Response (CESER) Portfolio}

- Cyber Security for Energy Delivery Systems (CEDS)

- Algorithms for optimal grid design to minimize the impact of cyber-physical attacks on the power grid

- Software and hardware to integrate Quantum Communication Transceivers and secure communications between locations

\section{- Infrastructure Security and Energy} Restoration (ISER)

- Data analytics and modeling to deliver a catalog of historical weather-related outage events- this information is integrated into EAGLE-I reports

- Electromagnetic Pulse/Geomagnetic Disturbance modeling and assessing the effects of E3 waveforms on the electric power system

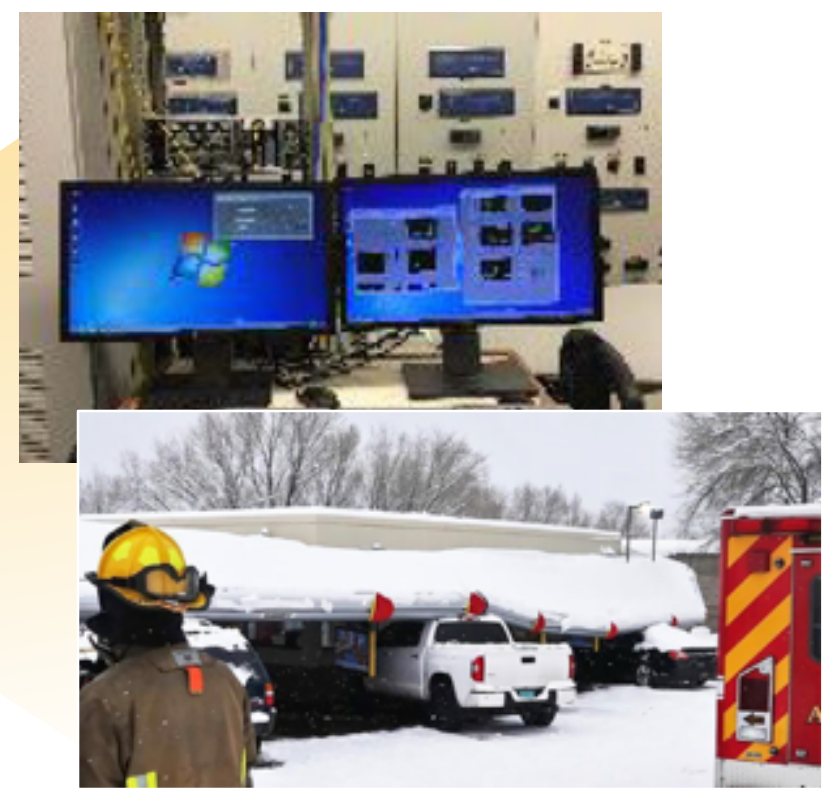

Preliminary testing on LANL electric grid successful; sustained operation over 13 days, including 40-inch snowfall. 


\section{Emerging Opportunities in CEDS}

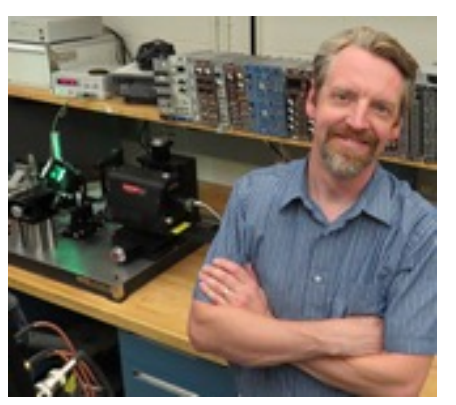

\section{Analysis on the Wire (AoW) Project (led by BNL)}

- As part of the Computational Science Initiative (CSI), the AOW project is building a prototype platform for in-network computing

- Possible applications for the smart grid (e.g. real/near-real time load forecasting and state estimation)

- Security is a challenge that could be addressed by leveraging LANL's miniaturized QKD capability, in combination with MDIQKD technology from ORNL

- Potential new project will couple these developments together with Stony Brook's room temperature quantum memories to develop a viable, implementable solution

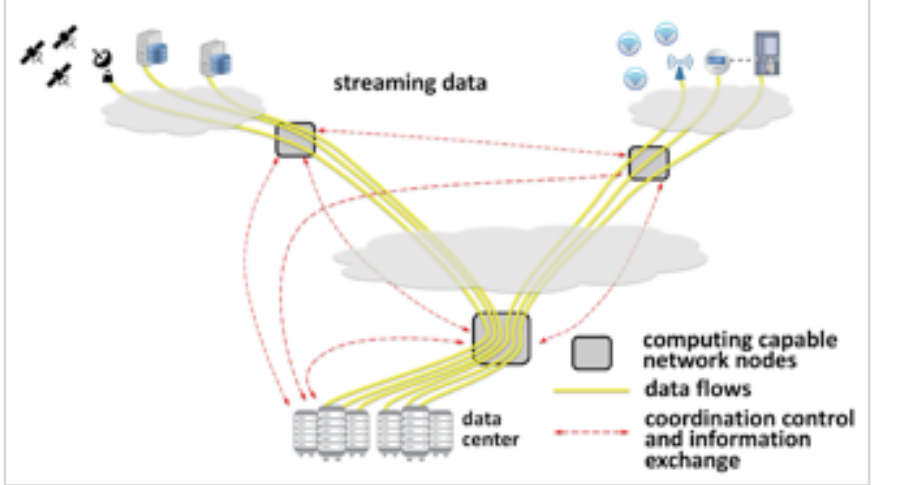

Security challenge: AoW nodes have to be privy to encryption keys to decrypt and process this data 


\section{Recent Growth in Our ARPA-E Portfolio}

\section{OPEN}

Advanced Manufacturing of Embedded Heat Pipe Nuclear Hybrid Reactor

DV Rao, PI; \$4.5M total; \$2.5M LANL

Partners: Westinghouse, U-Pitt, INL

Stable Diacid Coordinated Quaternary Ammonium Polymers for $\mathbf{8 0}-150^{\circ} \mathrm{C}$ Fuel Cells

Yu Seung Kim, PI; \$3.5 M total; \$1.8M LANL

Partners: Toyota, UNM, RPI

Making Demand-Response Work for a More Stable, Secure Energy Grid

Drew Geller, PI; \$600K LANL

Lead: U. Michigan

\section{MEITNER}

Self-regulating, Solid Core Block for a Walkaway Safe Heat Pipe Reactor

DV Rao, LANL PI; \$2.4M LANL

Lead: Westinghouse

\section{TOPICS}

Portable Neutron and Soft X-ray Diagnostics for Transformative Fusion-Energy Concepts

Glen Wurden, PI; \$630K LANL

Partners: University of Nevada-Reno

\section{DIFFERENTIATE}

Machine Learning Based Well Design to Enhance Unconventional Energy Production

Monty Vesselinov, PI; \$2.4M total; \$1.3M LANL Partners: MIT, Stanford, UNM, Julia Computing

\section{BETHE}

Target Formation and integrated Experiments for Plasma-Jet Driven Magneto-Inertial Fusion Samuel Langendorf, PI; \$4.6M total; \$1.9M LANL Partners: HyperJet Fusion Corporation, UNM, UAH, and Virginia Tech and State University

Electromagnetic \& Particle Diagnostics for Transformative Fusion-Energy Concepts

Glen Wurden, PI; \$375K total; \$300K LANL Partners: University of Nevada-Reno 


\section{Applied Energy Portfolio: Essential, Exciting, Impactful}

Four of the 11 LANL 2019 R\&D 100 Awards entries reflect innovation and collaboration in support of the national ENERGY SECURITY mission

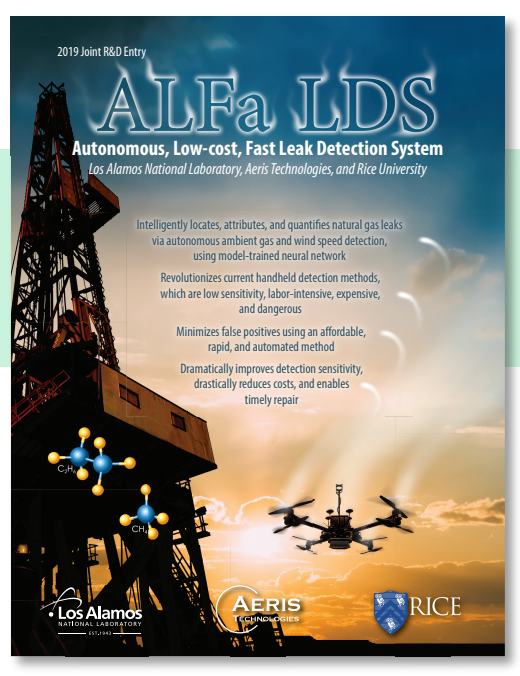

System intelligently locates, attributes, and quantifies natural gas leaks

Funded in part by ARPA-E

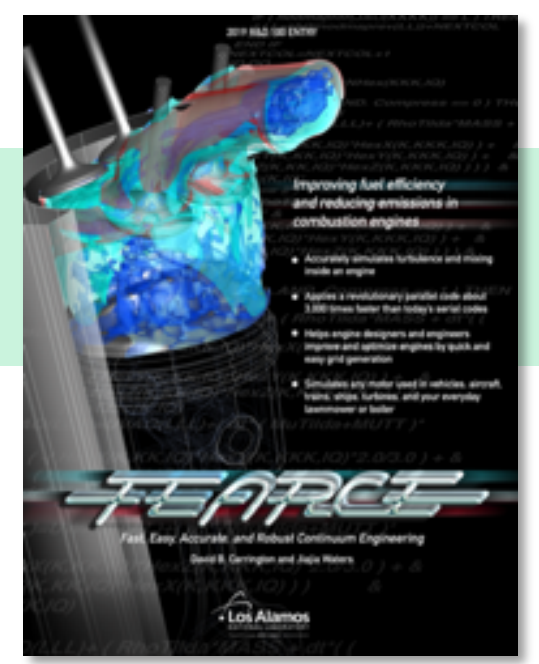

Software for engine designers to develop higher efficiency, lower emission vehicles

Funded by EERE

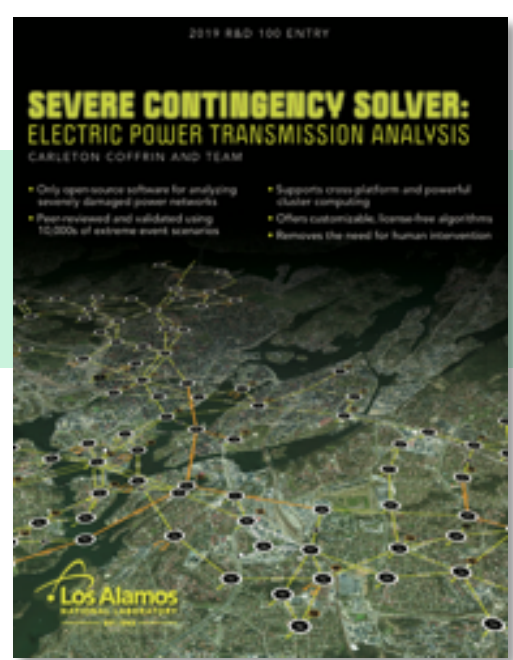

Software analyzes severely damaged electric power networks

Funded by Office of Electricity

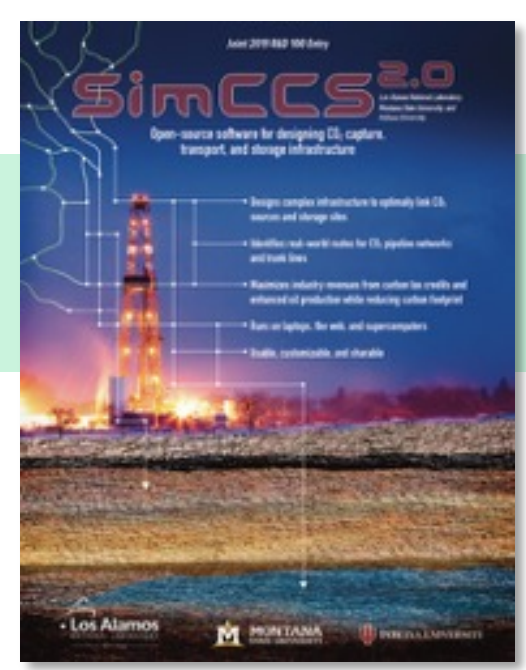

Software enables infrastructure design for $\mathrm{CO}_{2}$ capture, transport, storage

Funded by Office of Fossil Energy 